\title{
Morphology Characterisation of Pitting Corrosion on Sensitized Austenitic Stainless Steel by Digital Image Analysis
}

\author{
R. B. Ribeiro, ${ }^{1}$ J. W. J. Silva, ${ }^{1,2}$ L. R. O. Hein, ${ }^{2}$ M. C. Pereira, ${ }^{2}$ \\ E. N. Codaro, ${ }^{2}$ and N. T. Matias ${ }^{1}$ \\ ${ }^{1}$ Faculdades Integradas Teresa D'Ávila, FATEA-Rede salesianas, Avenida Peixoto de Castro 539, Vila Celeste, \\ 12606-580 Lorena, SP, Brazil \\ ${ }^{2}$ Universidade Estadual Paulista, UNESP-Campus de Guaratinguetá, Avenida Ariberto Pereira da Cunha 333, \\ Pedregulho, 12.516-410 Guaratinguetá, SP, Brazil
}

Correspondence should be addressed to J. W. J. Silva; jwjsilva@gmail.com

Received 30 May 2013; Accepted 14 July 2013

Academic Editors: G. Bereket, S. Caporali, and R. Salghi

Copyright (C) 2013 R. B. Ribeiro et al. This is an open access article distributed under the Creative Commons Attribution License, which permits unrestricted use, distribution, and reproduction in any medium, provided the original work is properly cited.

Pit morphology on sensitized 310S stainless steel has been studied using an image processing method based on reflected light microscopy. Salt Spray (fog) test has been used to induce the pitting corrosion. Morphological pits characters do not depend on sensitization heat treatments applied here. Nucleation rates and growth may be associated with quantity and distribution of chromium carbides. This being so, condition I (heating up to $1065^{\circ} \mathrm{C}$ during $1 \mathrm{~h}$ and air cooling) and condition II (heating up to $1065^{\circ} \mathrm{C}$ during $1 \mathrm{~h}$ and air cooling followed by reheating up to $670^{\circ} \mathrm{C}$ during $5 \mathrm{~h}$ and again air cooling) are the most susceptible to pitting, in particular the first one. In these two conditions, pits are nucleated in grains and in grain boundaries, while in condition III (heating up to $1065^{\circ} \mathrm{C}$ during $1 \mathrm{~h}$ and air cooling followed by reheating up to $620^{\circ} \mathrm{C}$ during $24 \mathrm{~h}$ and again air cooling), pits are preferentially nucleated in boundaries of small grains. Thence, pits usually grow more rapidly in depth than in width, being able to occur partial or total grains separation. Pits are mainly hemispherical, near-hemispherical, near-conical, and near-cylindrical without significant geometric transition associated with an increasing exposure period.

\section{Introduction}

Austenitic stainless steel is selected for corrosion resistance to the atmosphere and a vast variety of chemical products. This resistance is related to the formation of a thin and adherent oxides layer (mainly $\mathrm{Cr}_{2} \mathrm{O}_{3}$ ), which protects the surface against aggressive environments. The most common austenitic steel is iron-chromium-nickel alloys and they are widely known as the 300 series. These alloys usually contain between 16 and $30 \mathrm{wt} \%$ chromium, 8 to $20 \%$ nickel, and 0.03 to $0.1 \%$ carbon. With increasing chromium and nickel contents, this steel becomes increasingly resistant to pitting corrosion. However, the higher concentrations of these alloying elements result in lower carbon solubility and carbide segregation. Heat treatments, whether intentional or accidental, may provoke carbide precipitation at grain boundaries, often by causing steel to become susceptible to intergranular corrosion. In order to minimize carbide precipitation and prevent to sensitization, austenitic steel is frequently subjected to high-temperature solution treatment, commonly termed quench-annealing $[1,2]$. Pitting corrosion is observed in austenitic steel exposed to aqueous media containing chloride ions. This phenomenon almost always starts in anodic MnS inclusions and chromium-depleted zone adjacent to cathodic $\mathrm{M}_{23} \mathrm{C}_{6}(\mathrm{M}=\mathrm{Cr}$ or $\mathrm{Mo}$ ) precipitates, and it progresses inwards in intergranular or transgranular direction depending mainly on the steel microstructure $[2,3]$.

Many studies have been focused on the pit initiation and propagation mechanisms of this steel in chloride media [2-10], but relatively a few authors have considered the morphologic characteristics of pitting corrosion. It should be noted that pit growth rate depends on potential distribution inside the pit, which is determined by pit shape, especially by their width/depth aspect ratio [11, 12]. For pits initiated by electrochemical experiments, the pit depth or pit radius dependence on the immersion time $(t)$ may be expressed by 
the equation $k\left(t-t_{i}\right)^{n}$, where $t_{i}$ is the induction period, $k>0$, and $1 / 3 \leq n \leq 1$ are empirical constants which depend on chloride concentration, pits shape, and experimental conditions inherent of electrochemical methods. Pits are usually modelled as having cylindrical, hemispherical, or conical shapes, but in practice, they have a tendency to assume an irregular or not well-defined geometry associated with increasing size [13-15]. Therefore, equations, developed with these assumptions about shape, must be considered as only rough approximations.

In this study, a method based on image analysis has been used for the morphology characterization of pitting corrosion on sensitized 310S steel. For this purpose, pits have been initiated by Salt Spray exposure, and their temporal evolution has been examined by reflected light microscopy.

\section{Materials and Methods}

As-received, 310S plates [16] have been submitted to three solution heat treatment routines: heating up to $1065^{\circ} \mathrm{C}$ during $1 \mathrm{~h}$ and air cooling (condition I); heating up to $1065^{\circ} \mathrm{C}$ during $1 \mathrm{~h}$ and air cooling followed by reheating up to $670^{\circ} \mathrm{C}$ during $5 \mathrm{~h}$ and again air cooling (condition II); heating up to $1065^{\circ} \mathrm{C}$ during $1 \mathrm{~h}$ and air cooling followed by reheating up to $620^{\circ} \mathrm{C}$ during $24 \mathrm{~h}$ and again air cooling (condition III). The main purpose for annealing has been to produce a recrystallized microstructure with a uniform grain size and for dissolving detrimental chromium carbide precipitates. Then, a slow cooling or reheating within the range $550^{\circ}-800^{\circ} \mathrm{C}$ will lead to the rejection of carbon from solution, usually as the chromium-rich carbide, even when the carbon content of the steel is very low $(<0.05 \mathrm{wt} \%)$.

Specimens have been mechanically polished, and their microstructure has been chemically etched with the following solution: $10 \mathrm{~mL} \mathrm{HF}(48 \%)+10 \mathrm{~mL} \mathrm{HNO}_{3}(65 \%)+15 \mathrm{~mL} \mathrm{HCl}$ (35\%). Surfaces have been examined before and after Salt Spray tests [17] using a method of image analysis based on reflected light microscopy (LM). Images have been captured using a Nikon Epiphot 200 inverted metallurgical microscope coupled to a Diagnostic Instruments Insight Color QE digital camera. The NIH freeware program Image J [18] has been used for image processing, and a macroprogram has been developed to execute all processing and analysis steps. Quantitative parameters such as area at pit mouths, pit density, and corroded area have been systematically determined. Additionally, SEM and EDS combined techniques have been used to identify elemental composition of grains and grain boundaries. This surface analysis has been performed using a scanning electron microscope Leica Stereoscan 440 with a coupled energy dispersive spectrometer Oxford Link Exl II.

Pits morphological characteristics has been determined by specimens vertical sectioning, under low load and rotation in a precision saw, followed by fine grinding and polishing. To ensure low deformation of profile region, corroded surfaces have been covered with an epoxy resin before cutting and mounting with phenolic resin for mechanical polishing. Pitting analysis has been based mainly on Rectangularity or Area-Box $(A B)$ shape parameter, defined as the ratio between

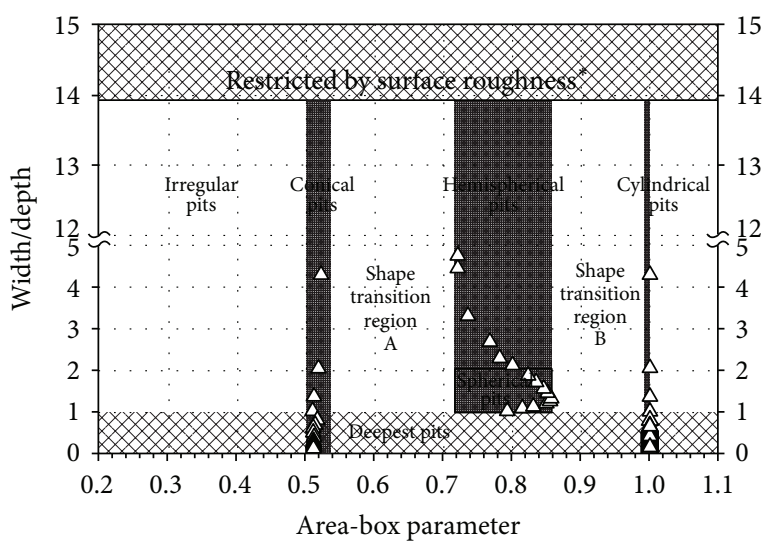

FIGURE 1: Diagram used for pit geometry classification. Width/depth aspect ratio versus area-box parameter.

pit area and minor surrounding rectangle area which encloses pit [19]. AB parameter is an effective geometry descriptor, permitting clear separation among conical pits $(0.5<\mathrm{AB}<$ $0.53)$, spherical or hemispherical pits $(0.72<\mathrm{AB}<0.86)$, and cylindrical pits $(A B \approx 1.0)$. Figure 1 summarizes the class for morphological analysis. Transition regions A (near-conical or near-hemispherical pits) and B (near-hemispherical or near-cylindrical pits) represent pits that can evolve for the best-defined geometries. Irregular pits (without geometric elements) present $\mathrm{AB}$ values lower than 0.5. To determine pits size, both pit width and depth the same as the rectangle mentioned above have been used. A representative number (60) of $1600 \times 1200 \times 8$ bit digital images under bright-field xenon-arc illumination has been obtained for each specimen.

\section{Results and Discussion}

Morphological and microstructural analysis has been carried out before and after Salt Spray test. Before corrosion test (Figures 2(a), 2(b), and 2(c)), conditions I, II, and III exhibit similar characteristics: a nonhomogeneous microstructure with an austenite phase, different orientation grains, carbide precipitates, and some holes probably provoked during the mechanical processing and metallographic preparation of steel. Austenite phase is present as equiaxed grains, many of which contain annealing twins. These twins are identified as bands with parallel sides and are formed when changes in the striking of atoms on close-packed (111) planes occur during recrystallization and grain growth [20]. EDS semiquantitative analysis on grain and grain boundary of condition II is showed in Figures 3(a) and 3(b). The most significant results are absence of molybdenum in steel and enrichment of chromium in precipitates on grain boundary. One explanation that the Mo peak was not detected is that it probably merges with the Ti peak. Also, it may be that the analysis has been punctual and not general.

Figures 4(a), 4(b), and 4(c) shows cross-section images of sensitized steel after $312 \mathrm{~h}$ of Salt Spray test, according to ASTM B117-11 [17]. The choice of time interval is empirical and is based on the following relationship: with increasing exposure time, changes occur in corrosion resistance 


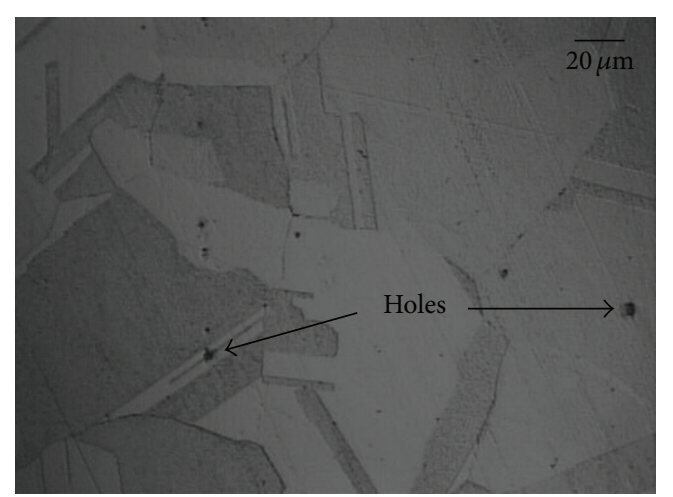

(a)

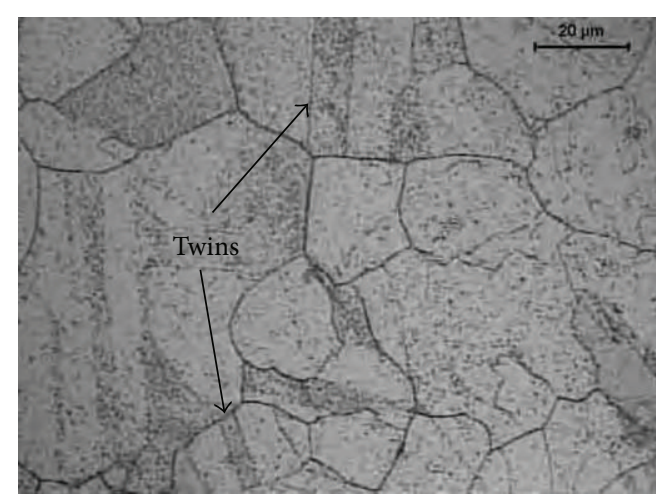

(b)

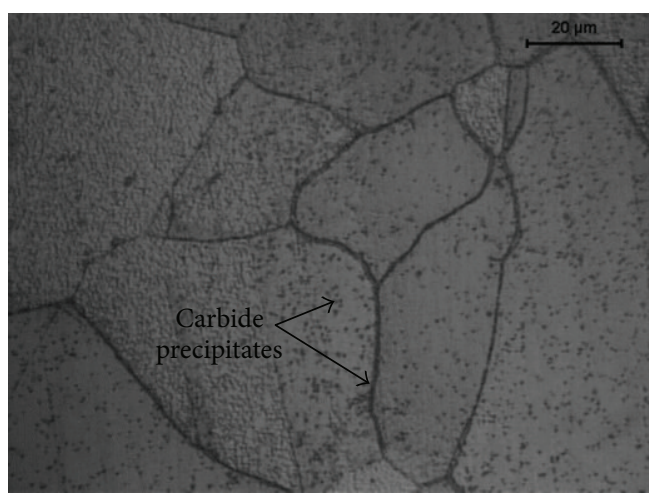

(c)

FIGURE 2: LM micrographs of 310S sensitized before Salt Spray test: (a) condition I, (b) condition II, and (c) condition III.

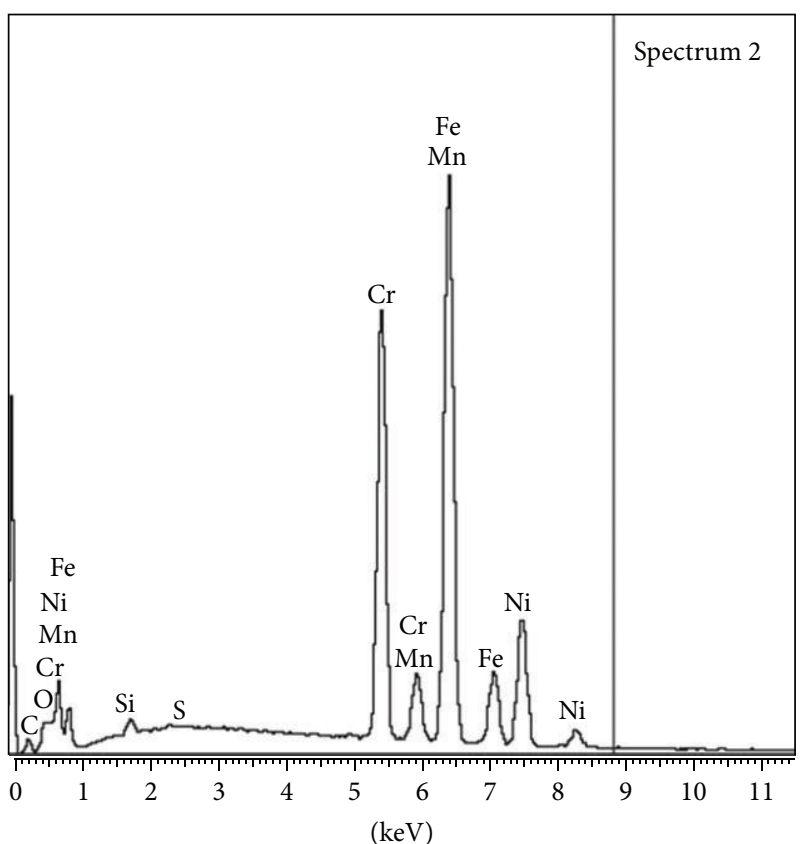

Full scale $14458 \mathrm{cts} \quad$ Cursor: $8.809 \mathrm{keV}(129 \mathrm{cts})$

(a)



Full scale $8698 \mathrm{cts}$ Cursor: $7.824 \mathrm{keV}(158 \mathrm{cts})$

(b)

FIGURE 3: EDS semiquantitative analysis upon the 310 S in condition II: (a) grain and (b) precipitate in grain boundary. 
TABLE 1: Variation of pitting corrosion parameters measured on exposed surfaces.

\begin{tabular}{|c|c|c|c|c|c|c|}
\hline \multirow{2}{*}{ Parameter } & \multirow{2}{*}{ Heat treatment } & \multicolumn{5}{|c|}{ Exposure period (h) } \\
\hline & & 48 & 120 & 168 & 216 & 312 \\
\hline \multirow{3}{*}{ Pit density $\left(\mathrm{mm}^{-2}\right)$} & I & 15.98 & 28.02 & 39.76 & 200.09 & 378.06 \\
\hline & II & 19.03 & 25.15 & 34.12 & 34.16 & 40.20 \\
\hline & III & 9.02 & 10.45 & 15.34 & 14.09 & 19.99 \\
\hline \multirow{3}{*}{ Corroded area (\%) } & I & 0.08 & 0.20 & 0.44 & 0.50 & 2.40 \\
\hline & II & 0.04 & 0.10 & 0.55 & 0.90 & 1.89 \\
\hline & III & 0.09 & 0.08 & 0.80 & 1.20 & 3.90 \\
\hline \multirow{3}{*}{ Area at mouth $\left(\mu \mathrm{m}^{2}\right)$} & I & 10.09 & 11.98 & 12.65 & 12.32 & 13.07 \\
\hline & II & 8.87 & 9.67 & 20.14 & 25.08 & 29.76 \\
\hline & III & 13.45 & 15.11 & 25.23 & 26.23 & 35.28 \\
\hline
\end{tabular}

TABLE 2: Classification and distribution of pits percentages.

\begin{tabular}{|c|c|c|c|c|c|c|}
\hline \multirow{2}{*}{ Pit geometry } & \multirow{2}{*}{ Heat treatment } & \multicolumn{5}{|c|}{ Exposure period (h) } \\
\hline & & 48 & 120 & 168 & 216 & 312 \\
\hline \multirow{3}{*}{ Irregular (\%) } & I & 6.41 & 0.67 & 0.66 & 4.19 & 0.00 \\
\hline & II & 1.71 & 7.43 & 3.75 & 5.36 & 6.67 \\
\hline & III & 0.00 & 3.17 & 15.87 & 6.44 & 12.30 \\
\hline \multirow{3}{*}{ Conical (\%) } & $\mathrm{I}$ & 1.28 & 4.67 & 1.32 & 2.80 & 1.23 \\
\hline & II & 0.00 & 6.93 & 5.00 & 2.68 & 1.02 \\
\hline & III & 0.00 & 2.08 & 2.59 & 13.30 & 6.56 \\
\hline \multirow{3}{*}{ Transition region A (\%) } & I & 7.70 & 54.66 & 14.47 & 26.57 & 3.47 \\
\hline & II & 20.50 & 24.36 & 24.16 & 27.68 & 30.45 \\
\hline & III & 18.14 & 27.09 & 26.98 & 61.80 & 39.33 \\
\hline \multirow{3}{*}{ Hemispherical (\%) } & I & 19.23 & 29.33 & 28.29 & 17.48 & 20.99 \\
\hline & II & 23.08 & 18.80 & 36.71 & 41.96 & 42.56 \\
\hline & III & 24.29 & 28.40 & 29.16 & 15.88 & 24.60 \\
\hline \multirow{3}{*}{ Transition region B (\%) } & I & 65.38 & 10.67 & 55.26 & 48.96 & 74.31 \\
\hline & II & 54.71 & 42.48 & 30.38 & 22.32 & 19.30 \\
\hline & III & 57.57 & 39.26 & 25.40 & 2.58 & 17.21 \\
\hline \multirow{3}{*}{ Cylindrical (\%) } & I & 0.00 & 0.00 & 0.00 & 0.00 & 0.00 \\
\hline & II & 0.00 & 0.00 & 0.00 & 0.00 & 0.00 \\
\hline & III & 0.00 & 0.00 & 0.00 & 0.00 & 0.00 \\
\hline
\end{tabular}

behaviour, in distribution, and in morphology of pits at material as received and treated.

After corrosion test, surfaces have revealed pits of different shapes and sizes. Table 1 permits to compare statistical parameters measured on exposed surfaces. For all heat treatment conditions, low values of corroded areas suggest there is a low probability of pit superposition during the exposure period. Thus, the temporal variation in pit density and pit area may be directly related to the rates of pit nucleation and two-dimensional growth, respectively. This way, nucleation rate has remained approximately constant for conditions II and III, and it has increased for condition I. In this last condition, the pits growth is slower. These facts are mainly related with a number of anodic sites and anodic/cathodic area ratio variation during exposure period.

Conditions I and II, pits are nucleated in grains and grain boundaries, while in condition III, pits are preferentially nucleated in boundaries of small grains. Generally, carbides are too fine to be resolved by reflected light microscope but are indirectly revealed by deep etching of affected grain boundaries (Figure 4(c)). Pits classification and distribution have been determined from cross-section images. Table 2 indicates that for all conditions: (i) the hemispherical, nearhemispherical, near-conical, and near-cylindrical pits represent more than $80 \%$ of the pit population; (ii) they appear not to undergo geometric transition associated with an increasing exposure period; (iii) pits with regular geometry represent less than $45 \%$ of pit population; (iv) cylindrical pits are absent. This geometry distribution may be attributed to similar microstructural characteristics of different heat treatment conditions.

Table 3 shows pit width and depth distributions. To diminish influence of preexisting holes and pits superposition on the count and statistical treatment of data, we have 
TABLE 3: Variation of pit width and depth with increasing exposure period.

\begin{tabular}{|c|c|c|c|c|c|c|c|}
\hline \multirow{2}{*}{ Pit geometry } & \multirow{2}{*}{ Heat treatment } & \multirow{2}{*}{ Parameter $(\mu \mathrm{m})$} & \multicolumn{5}{|c|}{ Exposure Period (h) } \\
\hline & & & 48 & 120 & 168 & 216 & 312 \\
\hline \multirow{6}{*}{ Irregular } & \multirow{2}{*}{ I } & Width & 7.12 & 14.88 & 11.73 & 5.74 & - \\
\hline & & Depth & 33.17 & 27.19 & 16.31 & 27.47 & - \\
\hline & \multirow{2}{*}{ II } & Width & 7.29 & 9.52 & 6.01 & 7.77 & 8.15 \\
\hline & & Depth & 11.01 & 9.80 & 23.32 & 15.19 & 25.26 \\
\hline & \multirow{2}{*}{ III } & Width & - & 6.65 & 6.35 & 7.04 & 6.96 \\
\hline & & Depth & - & 17.15 & 27.79 & 7.15 & 12.84 \\
\hline \multirow{6}{*}{ Conical } & \multirow{2}{*}{ I } & Width & 4.58 & 9.01 & 6.86 & 4.65 & 4.72 \\
\hline & & Depth & 21.46 & 14.59 & 6.29 & 11.77 & 18.60 \\
\hline & \multirow{2}{*}{ II } & Width & - & 6.51 & 4.79 & 4.57 & 5.02 \\
\hline & & Depth & - & 6.88 & 16.81 & 13.02 & 15.29 \\
\hline & \multirow{2}{*}{ III } & Width & - & 4.86 & 5.01 & 6.30 & 6.35 \\
\hline & & Depth & - & 20.62 & 19.60 & 6.46 & 8.78 \\
\hline \multirow{6}{*}{ Transition region A } & \multirow{2}{*}{ I } & Width & 4.74 & 6.89 & 6.64 & 4.38 & 6.34 \\
\hline & & Depth & 14.02 & 7.34 & 8.57 & 14.64 & 14.31 \\
\hline & \multirow{2}{*}{ II } & Width & 5.50 & 6.66 & 4.39 & 5.53 & 6.22 \\
\hline & & Depth & 10.50 & 6.88 & 15.00 & 10.68 & 12.99 \\
\hline & \multirow{2}{*}{ III } & Width & 4.37 & 5.71 & 4.17 & 6.06 & 5.80 \\
\hline & & Depth & 20.15 & 9.65 & 13.43 & 6.18 & 7.91 \\
\hline \multirow{6}{*}{ Hemispherical } & \multirow{2}{*}{ I } & Width & 4.82 & 6.02 & 5.89 & 3.91 & 3.67 \\
\hline & & Depth & 11.19 & 6.85 & 6.99 & 8.66 & 14.02 \\
\hline & \multirow{2}{*}{ II } & Width & 5.99 & 5.76 & 5.07 & 5.55 & 6.38 \\
\hline & & Depth & 9.16 & 6.32 & 10.13 & 7.54 & 10.28 \\
\hline & \multirow{2}{*}{ III } & Width & 3.24 & 4.97 & 5.01 & 5.54 & 4.88 \\
\hline & & Depth & 13.09 & 8.33 & 9.48 & 5.59 & 7.00 \\
\hline \multirow{6}{*}{ Transition region B } & \multirow{2}{*}{ I } & Width & 5.05 & 5.54 & 5.16 & 4.74 & 4.78 \\
\hline & & Depth & 5.40 & 5.21 & 4.73 & 5.16 & 5.91 \\
\hline & \multirow{2}{*}{ II } & Width & 5.65 & 4.52 & 6.60 & 6.36 & 6.37 \\
\hline & & Depth & 6.30 & 5.29 & 7.39 & 6.51 & 7.55 \\
\hline & \multirow{2}{*}{ III } & Width & 4.79 & 5.10 & 5.12 & 3.19 & 4.72 \\
\hline & & Depth & 5.64 & 6.01 & 6.14 & 5.98 & 4.91 \\
\hline \multirow{6}{*}{ Cylindrical } & \multirow{2}{*}{ I } & Width & - & - & - & - & - \\
\hline & & Depth & - & - & - & - & - \\
\hline & U & Width & - & - & - & - & - \\
\hline & & Depth & - & - & - & - & - \\
\hline & II & Width & - & - & - & - & - \\
\hline & 1111 & Depth & - & - & - & - & - \\
\hline
\end{tabular}

replaced the mean values by the medians [21]. Detailed analysis in this table indicates that for all conditions: (i) for each exposure period, width inside pit is in good agreement with the width at pit mouth estimated from Table 1 (supposing circular mouth); (ii) pit depth rapidly increases during the first 48 hours of Salt Spray exposure, and then it is apparently stabilized; (iii) pits are deeper than they are wide, which suggests that metal dissolution rate is higher at pit bottom than at the pit wall; (iv) pit depth increases from transition regions B to irregular geometry; (v) irregular pits are also the widest ones. This class of pits may have nucleated in holes (Figure 2(a)) and they have grown by an intergranular way and/or they have nucleated in boundaries of small grains and during their growth provoke grains separation, as showed in Figures 4(b) and 4(c). Although irregular pits represent a small percent of pit population, in practice, the maximum depth values are very important because the deepest pits can initiate cracks when steel is subjected to mechanical stress.

\section{Conclusions}

310S austenitic stainless steel sensitized by means of different heat treatments has exhibited similar microstructures and similar pits morphological characteristics after Salt Spray test. Nucleation rates and growth may be associated with quantity and distribution of chromium carbides. In this sense, 


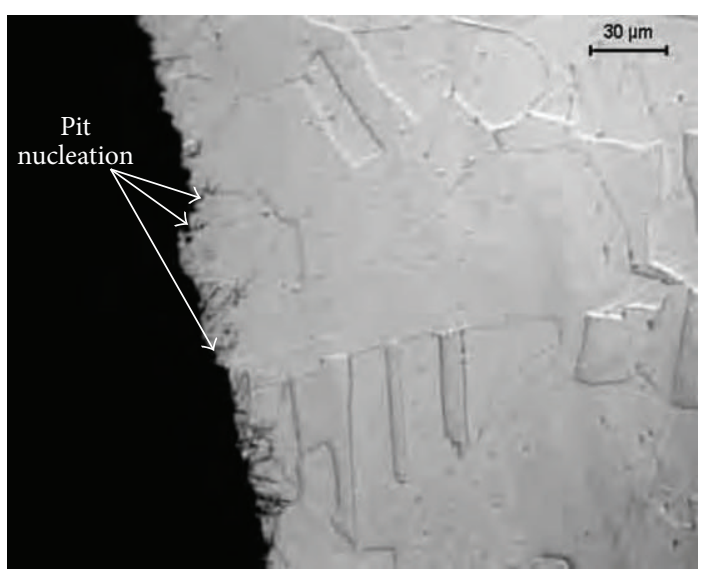

(a)

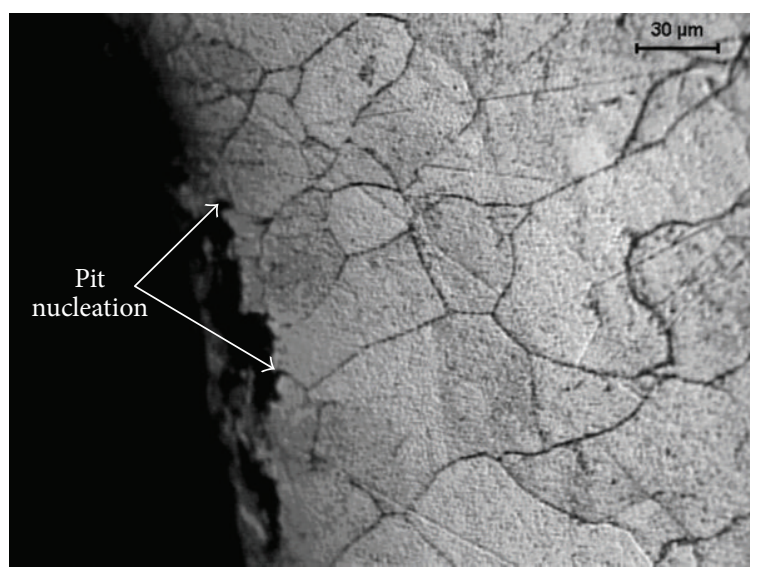

(b)

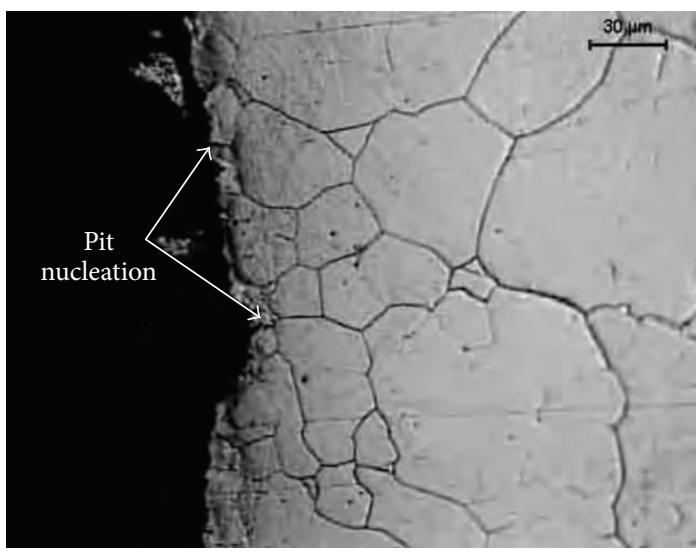

(c)

FIGURE 4: Cross-section images of $310 \mathrm{~S}$ sensitized after $312 \mathrm{~h}$ of Salt Spray test: (a) condition I, (b) condition II, and (c) condition III.

conditions I and II are the most susceptible to pitting, in particular the first one. In these two conditions, the pits are nucleated in grains and grain boundaries, while in condition III, pits are preferentially nucleated in boundaries of small grains. Then, the pits grow more rapidly in depth than in width being able to carry out the partial or total separation of grains. Pits are mainly hemispherical, near-hemispherical, near-conical, and near-cylindrical. However, irregular pits are also important because they are the deepest ones, which can initiate a stress-corrosion crack thus transforming one type of localised attack into another.

\section{Acknowledgments}

This research has been supported by FUNDUNESP (Process 01258/08-DFP) and CNPq (Process 305224/2004-2).

\section{References}

[1] H. K. D. H. Bhadeshia and R. W. K. Honeycombe, Steels, Microstructure and Properties, Butterworth-Heinemann, 3rd edition, 2011.

[2] P. Marcus, V. Maurice, and H.-H. Strehblow, "Localized corrosion (pitting): a model of passivity breakdown including the role of the oxide layer nanostructure," Corrosion Science, vol. 50, no. 9, pp. 2698-2704, 2008.

[3] A. Pardo, M. C. Merino, A. E. Coy, F. Viejo, R. Arrabal, and E. Matykina, "Pitting corrosion behaviour of austenitic stainless steels-combining effects of Mn and Mo additions," Corrosion Science, vol. 50, no. 6, pp. 1796-1806, 2008.

[4] L. Speckert and G. T. Burstein, "Combined anodic/cathodic transient currents within nucleating pits on Al-Fe alloy surfaces," Corrosion Science, vol. 53, no. 2, pp. 534-539, 2011.

[5] Z. Y. Liu, X. G. Li, and Y. F. Cheng, "Understand the occurrence of pitting corrosion of pipeline carbon steel under cathodic polarization," Electrochimica Acta, vol. 60, pp. 259-263, 2012.

[6] Z. Su, G. Hähner, and W. Zhou, "Investigation of the pore formation in anodic aluminium oxide," Journal of Materials Chemistry, vol. 18, no. 47, pp. 5787-5795, 2008.

[7] A. Pardo, M. C. Merino, A. E. Coy, R. Arrabal, F. Viejo, and E. Matykina, "Corrosion behaviour of magnesium/aluminium alloys in 3.5 wt.\% NaCl," Corrosion Science, vol. 50, no. 3, pp. 823-834, 2008.

[8] G. Lü, H. Cheng, C. Xu, and Z. He, "Effect of strain and chloride concentration on pitting susceptibility for type 304 austenitic stainless steel," Chinese Journal of Chemical Engineering, vol. 16, no. 2, pp. 314-319, 2008.

[9] H. M. Ezuber, "Influence of temperature and thiosulfate on the corrosion behavior of steel in chloride solutions saturated in CO2," Materials and Design, vol. 30, no. 9, pp. 3420-3427, 2009. 
[10] S. M. Ghahari, D. P. Krouse, N. J. Laycock et al., "Pitting corrosion of stainless steel: measuring and modelling pit propagation in support of damage prediction for radioactive waste containers," Corrosion Engineering Science and Technology, vol. 46, no. 2, pp. 205-211, 2011.

[11] H. W. Pickering, "The role of electrode potential distribution in corrosion processes," Materials Science and Engineering A, vol. 198, no. 1-2, pp. 213-223, 1995.

[12] G. Engelhardt, M. Urquidi-Macdonald, and D. D. Macdonald, "A simplified method for estimating corrosion cavity growth rates," Corrosion Science, vol. 39, no. 3, pp. 419-441, 1997.

[13] Standard Guide for Examination and Evaluation of Pitting Corrosion, ASTM G46-94, 1999.

[14] E. N. Codaro, R. Z. Nakazato, A. L. Horovistiz, L. M. F. Ribeiro, R. B. Ribeiro, and L. R. O. Hein, "An image analysis study of pit formation on Ti-6Al-4V," Materials Science and Engineering A, vol. 341, no. 1-2, pp. 202-210, 2003.

[15] T.-S. Huang and G. S. Frankel, "Influence of grain structure on anisotropic localised corrosion kinetics of AA7XXX-T6 alloys," Corrosion Engineering Science and Technology, vol. 41, no. 3, pp. 192-199, 2006.

[16] Standard Specification for Chromium and Chromium-Nickel Stainless Steels plate, sheet, and strip for pressure vessels and for general applications, ASTM A240/A240M-09a, 2009.

[17] Standard Practice for Operating Salt Spray (Fog) Apparatus, ASTM B117-11, 2011.

[18] W. S. Rasband, ImageJ, U.S. National Institutes of Health, Bethesda, Md, USA, 1997-2013, http://rsb.info.nih.gov/ij/.

[19] M. C. Pereira, J. W. J. Silva, H. A. Acciari, E. N. Codaro, and L. R. O. Hein, "Morphology characterization and kinetics evaluation of pitting corrosion of commercially pure aluminium by digital image analysis," Materials Sciences and Applications, vol. 3, pp. 287-293, 2012.

[20] G. Krauss, Steels, Heat Treatment and Processing Principles, chapter 12, ASM International, Novelty, Ohio, USA, 2000.

[21] G. C. Marano, R. Greco, and S. Sgobba, "A comparison between different robust optimum design approaches: application to tuned mass dampers," Probabilistic Engineering Mechanics, vol. 25, no. 1, pp. 108-118, 2010. 

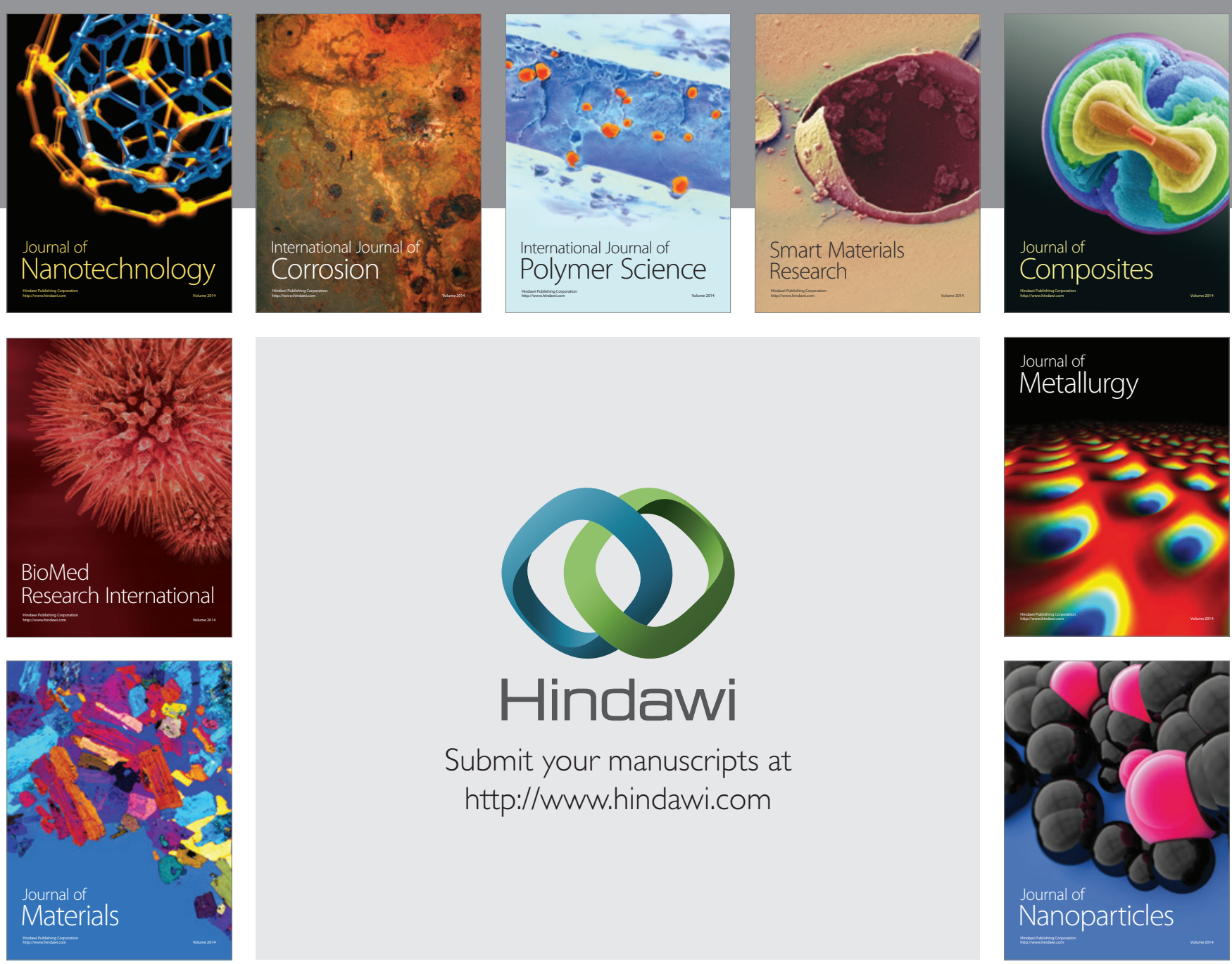

Submit your manuscripts at http://www.hindawi.com
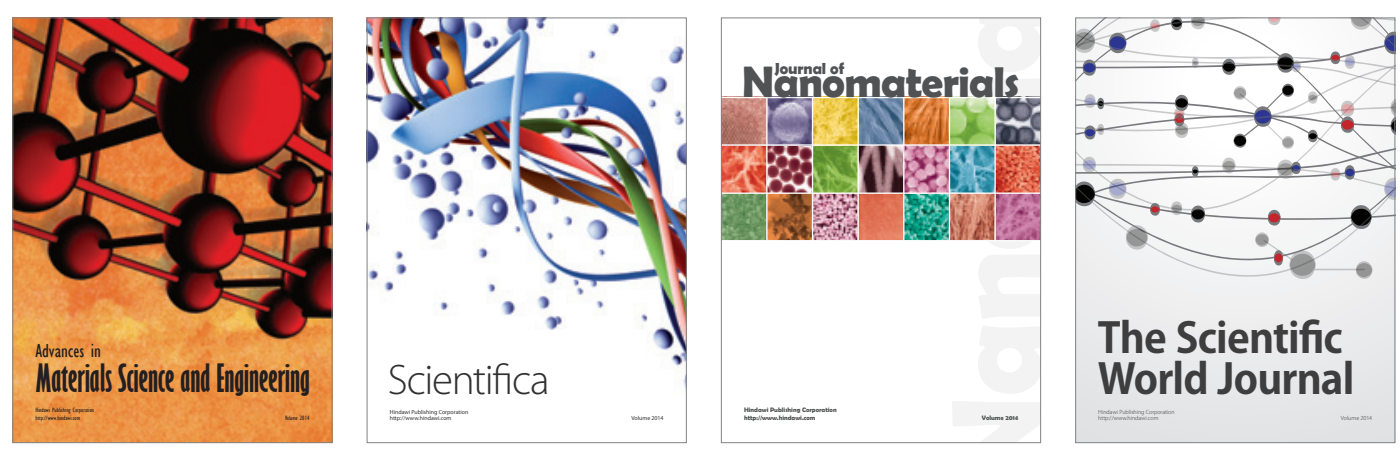

\section{The Scientific World Journal}
